\title{
The role of managed care pharmacy in coprescribing naloxone for patients with specific risk: recommendations from the AMCP Addiction Advisory Group
}

\author{
Jann B Skelton, BSPharm, MBA, FAPhA, and Vyishali Dharbhamalla, PharmD
}

\section{SUMMARY}

Prescription opioid misuse remains a significant cause of morbidity and mortality associated with drug overdose. Researchers, government agencies, public health interests, and professional organizations support the benefits of naloxone coprescribing for patients on chronic opioid therapy to prevent deaths from opioid overdose. However, gaps remain in the provision of naloxone to patients at risk. Currently, less than $1 \%$ of patients who should be prescribed naloxone with their opioid medications obtain a prescription for naloxone, illustrating an opportunity for health care providers to conduct thorough risk assessments for patients taking opioids and coprescribing naloxone to those at risk.

There are documented barriers to the provision of naloxone for primary care providers, pharmacists, and patients. Managed care organizations have also created barriers. To better understand and evaluate trends in treatment, coverage, policies, and needs associated with providing health services to patients with substance use disorders, the Academy of Managed Care Pharmacy (AMCP) Addiction Advisory Group conducted a survey in 2019. Eighty percent of the managed behavioral health organizations and $47 \%$ of AMCP payer members who responded to the survey encouraged naloxone coprescribing in patients at high risk of overdose; however, no organizations require coprescribing.

Health plans, managed care organizations, prescribers, pharmacists, patients, and others have important roles in decreasing the morbidity and mortality associated with opioid overdose. In particular, managed care organizations can take specific and meaningful actions to implement payment policies that improve naloxone coprescribing for patients at risk. In this article, opportunities have been outlined for managed care leadership that actively support public health policies for naloxone coprescribing, and 7 recommendations are presented.

\section{Author affiliations}

Jann B Skelton, BSPharm, MBA, FAPhA, Silver Pennies Consulting, Caldwell, NJ, and Vyishali Dharbhamalla, PharmD, Academy of Managed Care Pharmacy, Alexandria, VA.

AUTHOR CORRESPONDENCE:

Vyishali Dharbhamalla, 703.684.2633;

vdharbhamalla@amcp.org

J Manag Care Spec Pharm. 2022;28(1):100-06

Copyright $@ 2022$, Academy of Managed Care Pharmacy. All rights reserved.
Prescription opioid misuse remains a significant cause of morbidity and mortality associated with drug overdose. Drug overdose deaths continue to rise, with deaths increasing by $29.4 \%$ from December 2019 to December 2020. ${ }^{1}$ In the United States, drug overdose deaths increased by nearly $5 \%$ from 2018 to 2019 and have quadrupled since 1999. From 1999 to 2019, prescription overdose deaths quadrupled, with almost 247,000 Americans having died from overdoses related to the misuse and abuse of prescription opioids. ${ }^{2}$ Of note, there was a $20.4 \%$ decrease in prescription drug opioid deaths from 2017 to 2019, likely reflecting the changes in guidance that affected opioid prescribing practices. , $^{3,4}$

The financial costs of opioid overdose are also significant. A 2019 report showed that annual health care costs for patients who experienced an opioid overdose were \$1.94 billion across 647 health care facilities nationwide, based on data from 100,000 patients, with approximately 430,000 visits across various health care settings and within a mix of public and commercial insurance. ${ }^{5}$ Previous estimates of the annual excess costs of opioid abuse to payers range from approximately $\$ 10,000$ to $\$ 20,000$ per patient. ${ }^{6}$ 
In 2016, the Academy of Managed Care Pharmacy (AMCP) Addiction Advisory Group published the article "The Role of Managed Care Pharmacy in Improving Access to Naloxone," which outlined the issues of and barriers to receiving timely naloxone therapy, shared best practices within managed care, and highlighted opportunities for managed care to impact these complex issues. ${ }^{7}$ This article provides specific examples of opportunities for managed care organizations to improve access to naloxone and support patients with substance use disorder.

Although progress has been made in improving general naloxone access over the last 3 years, there are still significant opportunities to improve access for individuals at risk. ${ }^{8}$ The AMCP Addiction Advisory Group members feel that these recommendations are still worthy of note and would like to specifically focus on the opportunities and increased public health urgency for managed care to prevent opioid overdose deaths through the coprescribing of naloxone with prescription opioids.

\section{Naloxone Coprescribing for Patients at Risk for Opioid Overdose}

Researchers have demonstrated the benefits of naloxone coprescribing for patients on chronic opioid therapy within a paradigm of harm reduction. For example, a study of 164 patients who were educated about the risks of opioid overdose and provided naloxone rescue kits showed that no overdoses occurred in the high-risk study population. ${ }^{9}$ Another 2-year nonrandomized intervention study of 1,985 adults demonstrated that naloxone coprescribing is associated with reduced opioid-related emergency department visits. ${ }^{10}$ A retrospective cross-sectional study examined naloxone coprescribing in the general population and assessed how coprescribing varied by individual and community characteristics. ${ }^{11}$ Researchers found that coprescribing rates were low. The study authors recommended that states, insurers, and health systems implement strategies to facilitate increased coprescribing of naloxone to at-risk individuals. ${ }^{11}$

Because of the evidence of the benefit of coprescribing, numerous government, public health, and professional organizations have published statements supporting the coprescription of naloxone to prevent deaths from opioid overdose. ${ }^{12-20}$ Summaries of these statements are provided in Supplementary Table 1 (available in online article).

Notwithstanding the consistent and strong public statements supporting coprescription, there remains a gap in the provision of naloxone to patients at risk. According to the
US Department of Health and Human Services, less than 1\% of patients who should be prescribed naloxone with their opioid medications obtain a prescription for naloxone.12 This gap illustrates an opportunity for health care providers to conduct thorough risk assessments for patients taking opioids and coprescribing naloxone to those at risk.

\section{Improved Naloxone Access Through Pharmacies}

Pharmacists play an important role in preventing the misuse of opioids and ensuring that patients and their friends and families have access to naloxone. In fact, several studies have quantified the effect of pharmacists in improving naloxone coprescribing across a variety of practice settings. ${ }^{10,21-24}$ Pharmacists play an important role in preventing the misuse of opioids and ensuring patients and their friends and families have access to naloxone. Some of the professional activities that pharmacists can provide include screening and identifying patients at risk for opioid misuse; counseling patients on the careful and responsible use of opioids, to include the possibility of unintentional overdose; helping patients, friends, and family members know how to recognize and respond to opioid overdose; providing training in how to deliver the specific formulation of naloxone in the event of an overdose; dispensing naloxone to those with a prescription; and prescribing naloxone within the state practice authority to patients who present an opioid prescription..$^{24,25}$ In the New Mexico POINt-Rx Program, within community-based pharmacy, $62 \%$ of naloxone rescue kits were prescribed at the request of the patient, suggesting that patients might view pharmacists as an important access point for naloxone. ${ }^{24}$

There are published examples of increased access to naloxone by health-system pharmacies. One study evaluated patient education and prescribing of take-home naloxone for patients at risk for opioid overdose. ${ }^{26}$ These efforts educated 252 physicians, pharmacists, and nurses in overdose education and take-home naloxone and increased the number of naloxone prescriptions from 4.5 per month to an average of 46 per month within 3 months of implementation. A retrospective study of 817 patients within the Veterans Health Administration showed that screening patients for risk, providing education, and coprescribing naloxone for those at risk may be effective at reducing serious opioidrelated respiratory/central nervous system depression and overdose in medical users of prescription opioids. ${ }^{27}$

Since AMCP reviewed naloxone availability in 2016, there has been a significant increase in the availability of naloxone through community-based pharmacies across the 


\section{FIGURE 1 Coprescribing Requirements Within Managed Behavioral Health Organizations and Health Plans}

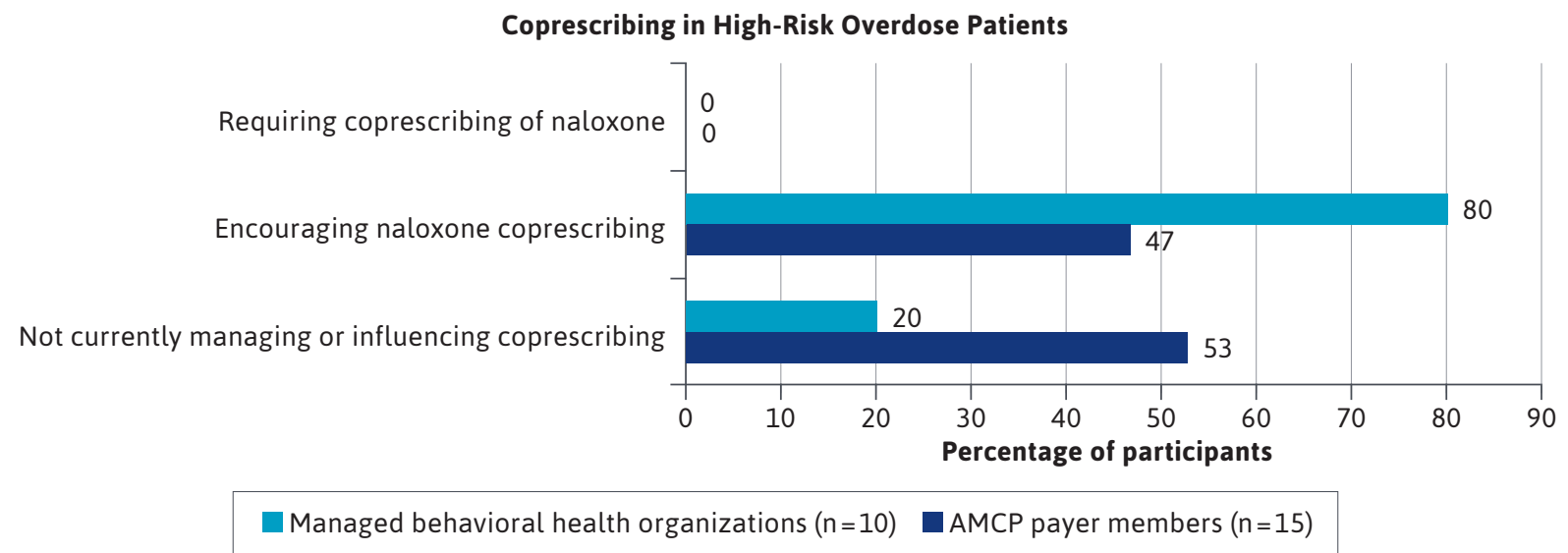

United States, with the National Alliance of State Pharmacy Associations reporting that there is now access to naloxone through community-based pharmacies in all 50 states.,28 $^{7,28}$ This access and authority are provided through a combination of statewide protocols, or standing orders; pharmacist prescribing; direct standing orders with physicians; and the ability to dispense naloxone without a prescription.

\section{Barriers to Naloxone Coprescribing}

Although naloxone coprescribing is accepted among many primary care providers, pharmacists, and patients, barriers remain to providing naloxone, including lack of training in the provision of naloxone, fear of offending patients, insurance costs, perception that prescribing naloxone takes too much time, payer logistics, and dispensing logistics within the pharmacy. ${ }^{29}$ Perceptions that offering the antidote could increase risky behavior is also considered a barrier for some providers. ${ }^{30}$

Some providers have concerns about legal risks associated with naloxone prescribing, particularly coprescribing naloxone to patients with pain, although, such concerns have been shown to be unfounded. ${ }^{31}$ The legal risk associated with prescribing naloxone is no higher than that associated with any other medication and is lower than many. According to the Substance Abuse and Mental Health Services Association, health care professionals concerned about legal risks associated with prescribing naloxone may be reassured that prescribing naloxone to manage opioid overdose is consistent with the drug's approved indication by the US Food and Drug Administration, resulting in no increased liability as long as the prescriber adheres to general rules of professional conduct. ${ }^{13}$

Kaiser Permanente published a study showing that clinical staff demonstrated substantial knowledge gaps about naloxone and its use in outpatient settings. ${ }^{32}$ It expressed uncertainty about who to prescribe naloxone to and identified a range of logistical barriers to its use in practice. Staff also described fears about offending patients and concerns about increased risk behaviors in patients prescribed naloxone. When considering naloxone, some providers reflected critically and with discomfort on their own opioid prescribing. These barriers were balanced by beliefs that prescribing naloxone could prevent death and result in safer opioid use behaviors. ${ }^{32}$

Key barriers from the perspective of pharmacists include lack of awareness, education and training to provide the service, variability in insurance coverage for naloxone by health insurances, misinformation about naloxone, preconceived attitudes towards the patient population, and $\operatorname{cost.}^{27,33}$ In addition, pharmacists prescribing naloxone spend additional time educating patients on its use, signs and symptoms of overdose, and other important counseling points, with difficulty obtaining pharmacist reimbursement for such services. ${ }^{25}$ Steep price increases in the cost of naloxone and higher copays have been identified by providers and pharmacists as barriers to providing naloxone to patients, close friends, and family members. Reimbursement for coprescribed naloxone, intended to be used by a patient or caregiver in the home, remains a barrier to access. ${ }^{34}$ In some cases, a payer may cover the medication but not the provider's time for training and education. 


\section{TABLE 1 AMCP Addiction Advisory Group Recommendations for Managed Care Leadership to Improve Access to Naloxone Through Coprescribing}

\begin{tabular}{|c|c|}
\hline Recommendation 1 & $\begin{array}{l}\text { Develop quality improvement or management strategies that mitigate the risk of opioid overdose through coprescribing } \\
\text { of naloxone when factors that could increase the risk of overdose are present (eg, history of substance use disorder, } \\
\text { opioid dosages over } 50 \text { morphine milligram equivalents/day, and/or concurrent benzodiazepine use). }\end{array}$ \\
\hline Recommendation 2 & $\begin{array}{l}\text { Develop and implement educational programs aimed at members of health plan pharmacy and therapeutics committees } \\
\text { and providers to reinforce the clinical benefit and the cost-effectiveness of naloxone coprescribing policies. }\end{array}$ \\
\hline Recommendation 3 & $\begin{array}{l}\text { Educate state legislative bodies about the value of coprescribing naloxone and the benefits of policy changes that } \\
\text { support this practice, including reimbursement requirements for standing orders. }\end{array}$ \\
\hline Recommendation 4 & $\begin{array}{l}\text { Implement mechanisms to intervene when a member has used naloxone, viewing it as a teaching moment and offering } \\
\text { opportunities to support members to seek treatment }\end{array}$ \\
\hline ation 5 & $\begin{array}{l}\text { Develop a payer toolkit that provides information and resources on coprescribing naloxone: } \\
\text { - Provide detailed information on the data/evidence for the value of coprescribing. } \\
\text { - Develop an easy-to-use resource which outlines the evidence on the types of patients who may be at risk for an opioid } \\
\text { overdose and may benefit from naloxone coprescribing. } \\
\text { - Develop a template letter to physicians, other prescribers and pharmacists, which could be modified by plans, that } \\
\text { focuses on the value of coprescribing and describes the patient risk factors for potential overdose. } \\
\text { - Ensure that materials reinforce to plans managing and offering behavioral health programs to patients with potential } \\
\text { substance use disorders the importance of not using prescription claim history as a proxy, since members may obtain } \\
\text { naloxone for various reasons. } \\
\text { - Identify and detail any cost-related evidence to support payer action to implement expanded policies on coprescribing } \\
\text { of naloxone. } \\
\text { - Develop materials/messages for patients and caregivers that can be distributed by health plans outlining risk factors } \\
\text { and the potential value of naloxone. }\end{array}$ \\
\hline Recommendation 6 & $\begin{array}{l}\text { Provide support, education, training, and reimbursement for providers who can assess patient risk using validated risk } \\
\text { indexes, such as the Risk Index for Overdose or Serious Opioid-Induced Respiratory Depression (RIOSORD), to estimate } \\
\text { the likelihood of life-threatening respiratory depression or overdose among medical users of prescription opioids. }{ }^{27,36}\end{array}$ \\
\hline Recommendation 7 & Develop and provide continuing education programs for plans, prescribers, and pharmacists on coprescribing. \\
\hline
\end{tabular}

There are also patient-centric barriers to the coprescribing of naloxone, which include limited education about opioid medication risks, limited knowledge of naloxone, medication cost, perceptions that overdose risk stems from medication misuse, and that providers might infer that patients were misusing their opioid medications if they accepted a naloxone prescription. ${ }^{35}$

\section{AMCP Stakeholder Survey Results on Coprescribing}

To better understand and evaluate trends in treatment, coverage, policies, and needs associated with providing health services to patients with substance use disorders, the AMCP Addition Advisory Group conducted a survey in 2019. The survey was fielded to 40 recruited individuals from 3 different stakeholder groups, including AMCP payer members $(n=15)$, addiction treatment providers $(n=15)$, and managed behavioral health organizations $(n=10)$.
Newly published information on the practice of coprescribing naloxone for patients prescribed opioids was rated as highly useful by a majority of stakeholders from all groups. In addition, information on educating patients on administration and identifying appropriate patients were rated as most useful. Eighty percent of the managed behavioral health organizations, and $47 \%$ of AMCP payer members who responded to the survey encouraged naloxone coprescribing in patients at high risk of overdose; however, no organizations required coprescribing (Figure 1).

In addition, while only $33 \%$ of managed care respondents acknowledged that the effect of bias, stigma, or negative connotations with substance use disorder affects payer coverage decisions, $50 \%$ of managed behavioral health organizations and $47 \%$ of addiction treatment providers perceived that these factors affected payer coverage decisions. 


\section{Outlining Opportunities for Managed Care Leadership}

The AMCP Addiction Advisory Group identified specific opportunities for managed care organizations to improve access to naloxone through coprescribing. These recommendations are listed and described in Table 1.

\section{Resources on Coprescribing Naloxone}

There are numerous resources available to assist plans, providers, and pharmacists in the coprescribing of naloxone. Example resources are provided in Supplementary Table 2 (available in online article).

\section{Conclusions}

Health plans, managed care organization, prescribers, pharmacists, patients, and others have unique and important roles to play in the nation's efforts to decrease the morbidity and mortality associated with opioid overdose. In particular, managed care organizations can take specific and meaningful actions to implement payment policies that improve coprescribing of naloxone for patients at risk. AMCP's Addiction Advisory Group has outlined opportunities for managed care leadership that actively support public health policies for naloxone coprescribing.

\section{DISCLOSURES}

The AMCP Addiction Advisory Group and the development of this article were supported by Alkermes and Precision Toxicology. Sponsors participated in the advisory group, which provided guidance in the development of the manuscript. Dharbhamalla is employed by AMCP. Skelton is a paid consultant working with $\mathrm{AMCP}$

\section{ACKNOWLEDGMENTS}

The following are members of the AMCP Addiction Advisory Group: Sherry Andes, BSPharm, PharmD, BCPS, BCPP, BCACP, BCGP, Sr. Managed Markets \& Health Outcomes Liaison, Acadia Pharmaceuticals; Amanda Bain, PharmD, MPH, MBA, Director, Pharmacy and Care Management, The Ohio State University Health Plan, Inc.; Christopher Beets, PharmD, MS, Clinical Pharmacist, Cigna-HealthSpring; Kelly J. Clark, MD, MBA, DFAPA, DFASAM, Founder, Addiction Crisis Solutions; MaryJean (MJ) Darby, RN Co-Founder and Chief Development Officer, Boulder; Michael V. Genovese, MD, JD, Chief Medical Officer, Behavioral Health, Acadia Healthcare; Gary M. Henschen, MD, LFAPA, Senior Vice President, Medical Director of Medical Management, Magellan Healthcare; Jim Hopsicker, RPh, MBA, Vice President, Pharmacy, MVP Health Care; Denise Kehoe, MBA, PhC, RPh, FAPhA, Consultant, BAR, LLC; Rob Laverty, MBA, Vice President, Market Access; Braeburn; Kimberly Lenz, PharmD, Clinical Pharmacy Manager, University of Massachusetts Medical School/ MassHealth; Shelby Morss, MBA, Associate Director, Policy and Payer Marketing; Alkermes, Inc.; Jake Nichols, PharmD, MBA, Owner \& CEO, Strategic Recovery Resources; Mark O'Brien, PharmD, MPH, Consultant Pharmacist, Aon; Kevin M. O'Neill, Vice President, National Accounts, Alkermes, Inc.; Penny Surratt, BSN, MBA, RN, Senior Director, Trade Relations, ReCept Healthcare Services, LP; Michael J. Tocco, RPh, MEd; President, Integrated Pharmacy Solution, Inc.; Daniel Tomaszewski, PharmD, PhD, Assistant Professor of Pharmacy Administration, Chapman University; and Michael Wascovich, PharmD, MBA, RPh, Senior Director, Pharmacy Services. Premier, Inc.

\section{REFERENCES}

1. Centers for Disease Control and Prevention, National Center for Health Statistics. Provisional drug overdose death counts. Reviewed July 14, 2021. Accessed July 30, 2021. https://www.cdc. gov/nchs/nvss/vsrr/drug-overdose-data. htm

2. Centers for Disease Control and Prevention. Drug overdose: overview. Reviewed March 17, 2021. Accessed July 30, 2021. https://www.cdc.gov/drugoverdose/deaths/prescription/overview.html

3. National Institute on Drug Abuse. Overdose death rates. Reviewed January 29, 2021. Accessed July 30, 2021. https:// www.drugabuse.gov/drug-topics/ trends-statistics/overdose-death-rates

4. Centers for Disease Control and Prevention. Prescribing practices: changes in opioid prescribing practices. Reviewed August 13, 2019. Accessed July 30, 2021. https://www.cdc.gov/drugoverdose/deaths/prescription/practices.html

5. Premier. Opioid overdoses costing U.S. hospitals an estimated \$11 billion annually. Press release. January 3, 2019. Accessed April 14, 2021. https://www.premierinc.com/newsroom/press-releases/ opioid-overdoses-costing-u-s-hospitalsan-estimated-11-billion-annually

6. Kirson NY, Scarpati LM, Enloe CJ, et al. The economic burden of opioid abuse: updated findings. J Manag Care Spec Pharm. 2017;23(4):427-45. doi:10.18553/ jmcp.2017.16265

7. Academy of Managed Care Pharmacy. The role of managed care pharmacy in improving access to naloxone: findings from the AMCP Addiction Treatment Advisory Group. December 2016. Accessed July 30, 2021. https://www.jmcp.org/pbassets/Outserts/The\%20Role\%20of\%20 Managed\%20Care\%20Pharmacy\%20\%20 -\%20Dec\%202016.pdf.

8. Centers for Disease Control and Prevention. Vital signs. Life-saving naloxone from pharmacies. Reviewed August 6, 2019. Accessed April 14, 2021. https:// www.cdc.gov/vitalsigns/naloxone/index. html 
9. Takeda MY, Katzman JG, Dole E, et al. Co-prescription of naloxone as a universal precautions model for patients on chronic opioid therapy-observational study. Subst Abus. 2016;37(4):591-96.

10. Coffin PO, Behar, Rowe C, et al. Nonrandomized intervention study of naloxone coprescription for primary care patients receiving long-term opioid therapy for pain. Ann Intern Med. 2016;165(4):245-52.

11. Stein BD, Smart R, Jones CM, Sheng F, Powell D, Sorbero M. Individual and community factors associated with naloxone co-prescribing among long-term opioid patients: a retrospective analysis. J Gen Intern Med. 2021;36(10):2952-57. doi:10.1007/s11606-020-06577-5

12. US Department of Health and Human Services. Naloxone: the opioid reversal drug that saves lives. December 2018. Accessed July 30, 2021. https://www.hhs. gov/opioids/sites/default/files/2018-12/ naloxone-coprescribing-guidance.pdf

13. Substance Abuse and Mental Health Services Administration. SAMHSA Opioid Overdose Prevention Toolkit. HHS Publication No. (SMA) 18-4742. 2018. Accessed November 30, 2021. https:// store.samhsa.gov/sites/default/files/d7/ priv/sma18-4742.pdf

14. American Pharmacists Association. Policy statement on controlled substances and other medications with the potential for abuse and use of opioid reversal agents. Reviewed 2018. Accessed July 30, 2021. https://www.pharmacist.com/ Portals/0/PDFS/HOD/1948\%20HOD\%20 Current\%20Adopted\%20Policy\%20 Web\%200223\%20removed\%202nd\%20 page.pdf?ver=rPuUtWyskyj1dgyPoErrw\%3d\%3d

15. Indian Health Service. How IHS is supporting HOPE. June 2020. Accessed July 30, 2021. https://www.ihs.gov/ sites/opioids/themes/responsive2017/ display_objects/documents/supportinghopeinfograph.pdf
16. The President's Commission on Combating Drug Addiction and the Opioid Crisis. Report on drug addiction and the opioid crisis. November 1, 2017. Accessed July 30, 2021. https://trumpwhitehouse. archives.gov/sites/whitehouse.gov/files/ images/Final Report Draft 11-15-2017. pdf

17. American Medical Association Opioid Task Force. Help save lives: co-prescribe naloxone to patients at risk of overdose. August 2017. Accessed July 30, 2021. https://www.end-opioid-epidemic. org/wp-content/uploads/2017/08/ AMA-Opioid-Task-Force-naloxone-onepager-updated-August-2017-FINAL.pdf

18. American Society of Addiction Medicine. Public policy statement on the use of naloxone for the prevention of opioid overdose deaths. Updated October 2016. Accessed July 30, 2021. https://www.asam.org/docs/defaultsource/public-policy-statements/ use-of-naloxone-for-the-prevention-ofopioid-overdose-deaths-final.pdf

19. Dowell D, Haegerich TM, Chou R. CDC guideline for prescribing opioids for chronic pain - United States, 2016. MMWR Recomm Rep. 2016;65 (No. RR-1):1-49.

20. U.S. Department of Health and Human Services, Office of the Surgeon General. Surgeon General's advisory on naloxone and opioid overdose. 2018. Accessed July 30, 2021. https://www.surgeongeneral. gov/priorities/opioid-overdose-prevention/naloxone-advisory.html

21. Duvivier H, Gustafson S, Greutman M, et al. Indian Health Service pharmacists engaged in opioid safety initiatives and expanding access to naloxone. J Am Pharm Assoc. 2017;57(2S):S135-S140.

22. Wilson CG, Rodriguez F, Carrington AC, Fagan EB. Development of a targeted naloxone coprescribing program in a primary care practice. J Am Pharm Assoc. 2017;57(2S):S130-S134.

23. Akers JL, Hansen RN, Oftebro RD. Implementing take-home naloxone in an urban community pharmacy. J Am Pharm Assoc. 2017;57(2S):S161-S167.
24. Bachyrycz A, Shrestha S, Bleske BE, et al. Opioid overdose prevention through pharmacy-based naloxone prescription program: innovations in healthcare delivery. Subst Abus. 2017;38(1):55-60.

25. Bailey AM, Wermeling DP. Naloxone for opioid overdose prevention: pharmacists' role in community-based practice settings. Ann Pharmacother. 2014;48(5):601-06.

26. Devries J, Rafie S, Polston G. Implementing an overdose education and naloxone distribution program in a health system. J Am Pharm Assoc. 2017;57(2S):S154-S160.

27. Zedler B, Xie L, Wang L, et al. Risk factors for serious prescription opioidrelated toxicity or overdose among Veterans Health Administration patients. Pain Med. 2014;15(11):1911-29.

28. National Alliance of State Pharmacy Associations. Pharmacist prescribing: naloxone. Accessed May 4, 2021. https:// naspa.us/resource/naloxone-accesscommunity-pharmacies/.

29. Behar E, Rowe C, Santos GM, et al. Acceptability of naloxone co-prescription among primary care providers treating patients on long-term opioid therapy for pain. J Gen Intern Med. 2017;32(3):291-95.

30. Peglow SL, Binswanger IA. Preventing opioid overdose in the clinic and hospital: analgesia and opioid antagonists. Med Clin North Am. 2018;102(4):621-34.

31. Davis CS, Burris S, Beletsky L, Binswanger I. Co-prescribing naloxone does not increase liability risk. Subst Abus. 2016;37(4):498-500.

32. Binswanger IA, Koester S, Mueller SR, et al. Overdose education and naloxone for patients prescribed opioids in primary care: a qualitative study of primary care staff. J Gen Intern Med. 2015;30(12):1837-44.

33. Zaller ND, Yokell MA, Green TC, Gaggin J, Case P. The feasibility of pharmacy-based naloxone distribution interventions: a qualitative study with injection drug users and pharmacy staff in Rhode Island. Subst Use Misuse. 2013;48(8):590-99. 
34. Seiler N, Horton, K, Malcarney MB. Medicaid reimbursement for take-home naloxone: a toolkit for advocates. Milken Institute School of Public Health. Accessed April 23, 2021. https:// prescribetoprevent.org/wp2015/

wp-content/uploads/naloxone medicaid report gwu.pdf
35. Mueller SR, Koester S, Glanz JM, Gardner EM, Binswanger IA. Attitudes toward naloxone prescribing in clinical settings: a qualitative study of patients prescribed high dose opioids for chronic non-cancer pain. J Gen Intern Med. 2017;32(3):277-83.
36. Zedler B, Saunders W, Joyce A, et al. Validation of a screening risk index for overdose or serious prescription opioid-induced respiratory depression [poster]. March 2015. Accessed April 23, 2021. http://paindr.com/wp-content/ uploads/2015/12/FINAL-RIOSORDAAPM-Poster-2-sided-3.pdf 